\title{
Five-year neurocognitive and health outcomes after the neonatal arterial switch operation
}

\author{
Ruth E. Neufeld, BSc, MCISc, MD, ${ }^{a}$ Brenda G. Clark, MD, ${ }^{\mathrm{a}}$ Charlene M. T. Robertson, MD, ${ }^{\mathrm{a}, \mathrm{b}}$ Diane M. Moddemann, MD, ${ }^{\mathrm{c}}$ \\ Irina A. Dinu, PhD, ${ }^{\mathrm{d}}$ Ari R. Joffe, MD, ${ }^{\mathrm{a}}$ Reg S. Sauve, MD, MSc, ${ }^{\mathrm{e}}$ Dianne E. Creighton, PhD, RPsych, ${ }^{\mathrm{e}}$ Lonnie Zwaigenbaum, MD, ${ }^{\mathrm{a}}$ \\ David B. Ross, MD, ${ }^{f}$ Ivan M. Rebeyka, MD, ${ }^{a, f}$ and the Western Canadian Complex Pediatric Therapies Follow-up Group*
}

Objectives: We sought to assess the 5-year neurocognition and health of an interprovincial inception cohort undergoing the arterial switch operation for transposition of the great arteries.

\begin{abstract}
Methods: Sixty-nine consecutive neonates had operations from 1996-2003 with full-flow cardiopulmonary bypass and selective deep hypothermic circulatory arrest. Outcomes were recorded at $58 \pm 9$ months of age. Univariate and multivariate analyses were used to identify outcome predictors, including surgical subtype and preoperative, operative, and postoperative variables.
\end{abstract}

Results: There was $1(1.5 \%)$ operative death. Two children were lost to follow-up, and 1 was excluded because of postdischarge meningitis. Outcomes are reported for 65 survivors. Two $(3 \%)$ children have cerebral palsy, and $7(11 \%)$ have language disorders, 4 of whom also meet the criteria for autism spectrum disorder. Two of the 4 children with autism have an affected older sibling. Of the 61 children without autism, scores approach those of peers, with a full-scale intelligence quotient of $97 \pm 16$, a verbal intelligence quotient of $97 \pm 18$, a performance intelligence quotient of $96 \pm 15$, and a visual-motor integration score of $95 \pm 16$. Mother's education, birth gestation or weight, and postoperative plasma lactate values account for $21 \%$ to $32 \%$ of the variance of these scores. Septostomy adds $7 \%$ to the variance of visual-motor integration scores.

Conclusions: Most preschool children do well after surgical correction for transposition of the great arteries, including complex forms. Potentially modifiable variables include high preoperative plasma lactate levels and septostomy. A minority of children were given diagnoses of language disorders, including autism, in which familial factors likely contribute to outcome.

\section{Supplemental material is available online.}

Neurodevelopmental outcome after surgical intervention for congenital heart disease is multifactorial, influenced by intrinsic characteristics of individual patients, and related to intraoperative and perioperative management and course. ${ }^{1,2}$

\footnotetext{
From the Department of Pediatrics, ${ }^{a}$ University of Alberta, Edmonton, Alberta, Canada; Pediatric Rehabilitation Outcomes Evaluation and Research, ${ }^{\mathrm{b}}$ Glenrose Rehabilitation Hospital, Edmonton, Alberta, Canada; the Department of Pediatrics, ${ }^{\text {c }}$ University of Manitoba, Winnipeg, Manitoba, Canada; the School of Public Health, ${ }^{\mathrm{d}}$ University of Alberta, Edmonton, Alberta, Canada; the Department of Pediatrics, ${ }^{\mathrm{e}}$ University of Calgary, Calgary, Alberta, Canada; and the Department of Surgery, ${ }^{\mathrm{f}}$ University of Alberta, Edmonton, Alberta, Canada.

Supported initially by the Glenrose Rehabilitation Hospital Research Trust Fund with ongoing support from the Registry and Follow-up of Complex Pediatric Therapies Project, Alberta Health and Wellness.

No reprints will be available from the authors.

*P. Blakely, Saskatoon, Saskatchewan, Canada; A. Ninan, Regina, Saskatchewan, Canada.

Received for publication Jan 8, 2008; revisions received March 28, 2008; accepted for publication May 4, 2008.

Address for correspondence: Charlene M. T. Robertson, MD, Room 242, GlenEast, Glenrose Rehabilitation Hospital, 10230-111 Avenue, Edmonton, Alberta T5G 0B7, Canada (E-mail: charlene.robertson@capitalhealth.ca).

J Thorac Cardiovasc Surg 2008;136:1413-21

$0022-5223 / \$ 34.00$

Copyright (C) 2008 by The American Association for Thoracic Surgery

doi:10.1016/j.jtcvs.2008.05.011
}

Long-term follow-up of children who underwent the arterial switch operation (ASO) for correction of transposition of the great arteries (TGA) reveals small but important differences from general population normative data in cognitive function, motor skills, academic achievement, language ability, and behavior. ${ }^{3-10}$ Some deficits become apparent only at school age, when the child is required to perform more complex cognitive, social, and linguistic skills that contribute to the development of peer relationships and literacy. ${ }^{11,12} \mathrm{Re}$ sults of a study at our institution demonstrated improved early motor outcomes in a cohort of children who had undergone the ASO compared with children from earlier surgical eras at other institutions. ${ }^{13}$ In this article we describe the neurocognitive and health outcomes at 5 years of age for a subset of that cohort who underwent surgical intervention between 1996 and 2003.

\section{MATERIALS AND METHODS}

This interprovincial inception cohort outcomes study enrolled 69 consecutive neonates undergoing the ASO for repair of TGA from September 1996 through May 2003 at Stollery Children's Hospital, Edmonton, Alberta, Canada. Based on the complexity of their cardiac anomalies, children were divided into 3 groups: group A, simple TGA with intact ventricular septum $(\mathrm{n}=38)$; group $\mathrm{B}$, TGA with ventricular septal defect (VSD; $\mathrm{n}=20)$; and group $\mathrm{C}$, complex TGA $(\mathrm{n}=11)$. Additional anatomic diagnoses in group $\mathrm{C}$ included double-outlet right ventricle, single coronary artery, interrupted aortic arch, aortic coarctation or hypoplastic aortic arch, pulmonary artery anomaly, and left ventricle outflow tract obstruction or aortic stenosis. Two cardiac surgeons did the repairs. Operative procedures included 


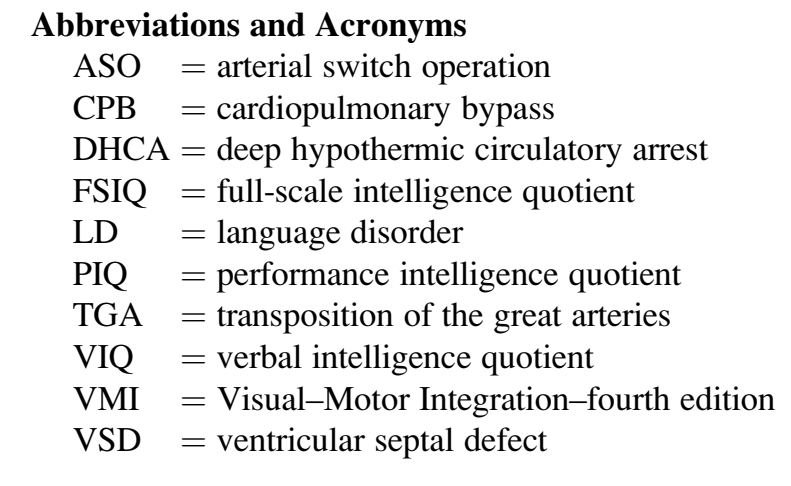

predominantly full-flow $\left(150 \mathrm{~mL} \cdot \mathrm{kg}^{-1} \cdot \mathrm{min}^{-1}\right)$ cardiopulmonary bypass (CPB), with a target hematocrit value of greater than $0.25 \%$, moderate hypothermia with selective use of deep hypothermic circulatory arrest (DHCA), and a modified $\mathrm{pH}$-stat strategy used for cooling. The venous cannulation strategy varied throughout this period based on surgeon preference, with either a single venous cannula or bicaval cannulation used for simple TGA. Complex transpositions were repaired with bicaval cannulation. Intraoperative lactate measurements were not consistently done.

Prospectively collected predictor variables included patient and family demographics (sex, socioeconomic status, ${ }^{14}$ maternal education, and year of operation), factors related to preoperative health status (antenatal diagnosis, use of balloon septostomy, ventilation time, age at operation, gestational age, and birth weight), preoperative and early and late postoperative measures of illness severity (highest dopamine level used, highest plasma lactate value, and lowest base deficit), operative variables (CPB time, lowest flow for $>10$ minutes on bypass, crossclamp time, DHCA time [if used], lowest temperature in degrees Celsius, and repeat CPB, if needed), and overall duration of ventilation, hospital days, presence of convulsions, or need for cardiopulmonary resuscitation, extracorporeal membrane oxygenation, or reintervention (see Table E1). The cohort was assessed at 6 to 10 months of age, 18 to 24 months of age (as previously reported ${ }^{13}$ ), and 4 to 6 years (range, 47.8-76.3 months) of age.

\section{Outcome Assessment}

Neurocognitive, neurologic, and health status outcomes were assessed at $58 \pm 9$ months of age by multidisciplinary neurodevelopmental teams at one of 5 centers in Western Canada: Calgary and Edmonton, Alberta; Regina and Saskatoon, Saskatchewan; and Winnipeg, Manitoba. History of hospitalizations, illnesses, medication use, and growth parameters, as well as family socioeconomic status ${ }^{14}$ and maternal education (years of schooling), were recorded (Table 1). Physicians experienced in neurodevelopmental follow-up examined each child, as previously described. ${ }^{10,13}$ Motor or sensory impairment was diagnosed if a child had cerebral palsy, visual impairment (corrected visual acuity in the better eye $<20 / 60$ ), or sensorineural hearing loss (responses $>25 \mathrm{~dB}$ hearing level at any frequency from 250 $4000 \mathrm{~Hz}$ ). Hearing was evaluated by certified audiologists. Experienced pediatric psychologists or psychometrists assessed cognitive ability and visual-motor skills by using current age-appropriate standardized measures, including the Weschler Preschool and Primary Scales of Intelligence-third edition $^{15}$ and the Beery-Buktenica Developmental Test of Visual-Motor Integration-fourth edition (VMI; Table 2). ${ }^{16}$ Variables included the United States normed full-scale intelligence quotient (FSIQ), verbal intelligence quotient (VIQ), performance intelligence quotient (PIQ), and VMI, each expressed as a standard score with a mean of 100 and standard deviation of 15 .

Speech and language concerns were identified by means of a 2-stage process. Children were assessed during cognitive evaluations, with further assessments completed by certified speech-language pathologists when concerns were identified. Speech disorders (articulation and phonologic), language delay (slower rate of language development but with typical sequence), ${ }^{17}$ or language disorder (LD; deviation from typical rate and sequence of acquisition of specific language skill) ${ }^{17}$ were diagnosed by speech-language pathologists based on clinical judgment informed by the results of standardized tests (Table 3 and see Table E2).

Children with LD were referred for further diagnostic assessment. Autism spectrum (hereafter autism) diagnoses were established based on structured clinical interview and behavioral observation (including the Autism Diagnostic Observation Schedule), ${ }^{18,19}$ with clinical best diagnostic estimate based on the Diagnostic and Statistical Manual of Mental Disorders, fourth edition. ${ }^{20}$

Ethics board approval was obtained from each site, and all parents or guardians provided written informed consent. The funding agency has had no role in the data interpretation.

\section{Statistics}

One-way analysis of variance with Tamhane's post-hoc multiple comparisons, $t$ tests, $\chi^{2}$ analysis, and Fisher's exact tests (all 2 sided) were used to compare groups; the Bonferonni correction was applied. Psychologic test results are given for the total group and for those without and with LD. In addition, predictions of outcome were determined separately for children without and with autism.

To screen for variables associated with psychologic scores, we used linear regression analysis. Multiple regression models consisted of variables found significant at a $P$ value of .10 or less in the univariate analysis after screening for multicolinearity.

To screen for variables associated with autism, we used univariate logistic regression models. The final multiple logistic regression consisted of variables found significant at a $P$ value of less than .10 in the univariate analysis after screening for multicolinearity.

Regression model results are reported as effect sizes (for psychologic scores) and odds ratios (for autism), along with confidence intervals and $P$ values. Stepwise multiple regressions were used to explore the change in the percentage of variation in outcomes explained by each additional predictor to a significance level of $.05 .^{21}$ Statistical analyses were performed with SAS version 9.1 (SAS Institute, Inc, Cary, NC).

\section{RESULTS \\ Description of Cohort}

Of the 69 neonates, outcomes are reported for 65 children. One child with a complex lesion of the interrupted aortic arch, right ventricular outflow tract obstruction, and coronary artery anomalies died on postoperative day 22 after cardiopulmonary resuscitation and redo surgical intervention for right ventricular outflow tract obstruction. A second child was excluded because of problems unrelated to surgical treatment; this child had postdischarge bacterial meningitis with cerebral vasculitis and infarction, mild left lower extremity spastic monoplegia, low intelligence scores, and right profound sensorineural hearing loss. Preschool outcome information is not available for 2 children with operations within this time period; both were free of motor and sensory disability at 18 months of age.

Table E1 shows the background characteristics of the 65 five-year-old children after the neonatal ASO in relation to type of operation. Fewer neonates undergoing the ASO and VSD repair required any DHCA. Those undergoing complex repairs were more likely to require repeat $\mathrm{CPB}$ and longer crossclamp times. 
TABLE 1. Five-year health, growth, and development after the neonatal arterial switch operation in relation to the complexity of cardiac anomaly $(\mathbf{n}=65)$

\begin{tabular}{|c|c|c|c|c|c|c|}
\hline & Total $(\mathbf{n}=\mathbf{6 5})$ & $\operatorname{ASO}(\mathbf{n}=36)$ & ASO/VSD $(\mathbf{n}=19)$ & Complex $(\mathbf{n}=10)$ & $\chi^{2}$ & $P$ value* \\
\hline Height $<5$ th percentile & $2(3 \%)$ & $0(0 \%)$ & $2(11 \%)$ & $0(0 \%)$ & 4.996 & .082 \\
\hline Weight $<5$ th percentile & $3(6 \%)$ & $1(3 \%)$ & $1(5 \%)$ & $1(10 \%)$ & 0.953 & .621 \\
\hline Microcephaly & $2(3 \%)$ & $1(3 \%)$ & $1(5 \%)$ & $0(0 \%)$ & 0.663 & .729 \\
\hline Specialists regularly seen: $>2$ & $10(15 \%)$ & $7(70 \%)$ & $2(20 \%)$ & $1(10 \%)$ & 1.023 & .600 \\
\hline Current medication for chronic lung disease & $6(9 \%)$ & $4(11 \%)$ & $1(5 \%)$ & $1(10 \%)$ & 0.516 & .773 \\
\hline Current medication for heart disease & $4(6 \%)$ & $1(3 \%)$ & $2(11 \%)$ & $1(10 \%)$ & 1.596 & .450 \\
\hline Visual impairment $(<20 / 60)$ & $1(2 \%)$ & $0(0 \%)$ & $0(0 \%)$ & $1(10 \%) \dagger$ & 5.586 & .061 \\
\hline Strabismus & $5(8 \%)$ & $1(3 \%)$ & $1(5 \%)$ & $3(30 \%)$ & 8.391 & .015 \\
\hline Cerebral palsy & $2(3 \%)$ & $1(3 \%) \ddagger$ & $0(0 \%)$ & $1(10 \%) \S$ & 2.221 & .329 \\
\hline Sensorineural hearing loss & $2(3 \%)$ & $2(6 \%)$ & $0(0 \%)$ & $0(0 \%)$ & 1.662 & .436 \\
\hline Bilateral & $1(2 \%)$ & $1(3 \%) \|$ & $0(0 \%)$ & $0(0 \%)$ & & \\
\hline Unilateral & $1(2 \%)$ & $1(3 \%) \Phi$ & $0(0 \%)$ & $0(0 \%)$ & & \\
\hline Epilepsy & $2(3 \%)$ & $1(3 \%) \#$ & $1(5 \%)^{* *}$ & $0(0 \%)$ & 0.633 & .729 \\
\hline Language/speech abnormality $\dagger \dagger$ & $17(26 \%)$ & $12(33 \%)$ & $3(16 \%)$ & $2(20 \%)$ & 2.214 & .331 \\
\hline Speech sound disorder & $3(5 \%)$ & $3(8 \%)$ & $0(0 \%)$ & $0(0 \%)$ & & \\
\hline Language disorder & $7(11 \%)$ & $5(14 \%)$ & $2(11 \%)$ & $0(0 \%)$ & & \\
\hline Language delay as expected & $7(11 \%)$ & $4(11 \%)$ & $1(5 \%)$ & $2(20 \%)$ & & \\
\hline
\end{tabular}

Note: After the Bonferonni correction, $P$ values of .004 or less remain significant. Also, all children were receiving an appropriate oral diet for age with no additional supplements; 6 children had oral supplements at less than 6 months of age. No child required supplemental oxygen. ASO, Isolated arterial switch operation; ASO/VSD, ASO with ventricular septal defect repair. ${ }^{*} \chi^{2}$ Analysis. $\dagger$ Ocular albinism. $\ddagger$ Mild left spastic hemiplegia, ambulatory without aids, preoperative right middle cerebral artery infarction. $\S$ Spastic ambulatory cerebral palsy, ambulatory without aids, preoperative dural sinus thrombosis. ||Bilateral mild-to-moderate high-frequency sensorineural hearing loss. $\uparrow$ Right unilateral profound sensorineural hearing loss. \#Focal seizures, normal magnetic resonance imaging results, language disorder, autism, spectrum disorder. $* *$ Atypical absence epilepsy, receiving antiepileptics, normal magnetic resonance imaging results, language disorder. $\dagger \dagger$ Language and speech were screened during the psychologic assessment: 40 children were considered to have normal language and speech, 8 others were referred to a speech-language pathologist with normal results, and 17 others were assessed as having an abnormality by 1 or more speech-language pathologists.

\section{Health, Growth, and Impairment Outcomes}

Table 1 shows the health, growth, and impairment outcomes of these children at 5 years of age. The surgical subtype did not define outcomes. For one child, we confirm ambulatory cerebral palsy reported at 18 months. ${ }^{13}$ That child had complex surgical intervention but without septostomy, a normal preoperative plasma lactate value, and a dural sinus thrombosis found on preoperative imaging. At 5 years of age, another child was given a diagnosis of mild left spastic hemiplegia. This second child had balloon septostomy, preoperative right middle cerebral artery infarction on brain imaging, and an increased preoperative plasma lactate value.

\section{Neurocognitive Outcomes}

Table 2 shows the psychologic scores for the entire cohort. There were no significant differences in relation to surgical subgroups, although scores for the ASO with VSD repair group are closest to normative values.

Further analyses of the $7(11 \%)$ of 65 children (shown in Table 1) with LD was required. Psychologic scores of children with and without LD in relation to surgical subtype are shown in Table 2. For 58 children without LD, there were no differences in relation to surgical subtype. LD were found only in the children undergoing the ASO with and without VSD, with no difference between these 2 surgical subtypes.
Comparisons between the 58 children without LD and the 7 with LD were as follows: FSIQ-98 \pm 16 (no LD) versus $76 \pm 23$ (LD), $t=2.444, P=.046$; VIQ-98 \pm 17 (no LD) versus $69 \pm 19(\mathrm{LD}), t=4.329, P<.001$; PIQ-96 \pm 15 (no $\mathrm{LD}$ ) versus $85 \pm 26(\mathrm{LD}), t=1.079, P=.319$; and $\mathrm{VMI}-94 \pm 14$ (no LD) versus $85 \pm 31$ (LD), $t=6.282$, $P=.415$. Similarly, the proportion of scores less than 2 standard deviations (SDs) below the mean (IQ $<70$ ) was affected by children with LD as follows: FSIQ-1 $(2 \%$; no LD) versus $3(43 \%$; LD), sig $=.003$; VIQ-6 $(10 \%$; no LD) versus $3(43 \%$; LD), sig $=.050$; PIQ-3 $(5 \%$; no LD) versus 2 $(29 \%$; LD), sig $=.086$; and VMI-2 $(3 \%$; no $\mathrm{LD})$ versus $2(29 \% ; \mathrm{LD}), \mathrm{sig}=.054$.

\section{Subgroup With LDs}

Results of further assessment of the 7 children with LDs are reported in Table 3. All 7 children had a normal examination result at 7 to 10 months of age by a neurodevelopmental pediatrician, nurse, audiologist, and physical therapist. All 7 children had a multidisciplinary assessment at age 5 years, and all had normal hearing. Six of these 7 children were available for further assessment. Four $(6.1 \%)$ children received a Diagnostic and Statistical Manual of Mental Disorders, fourth edition, diagnosis of autism by an expert multidisciplinary team consisting of a neurodevelopmental pediatrician, speech-language pathologist, and psychologist. 
TABLE 2. Five-year psychologic test results in relation to type of cardiac lesion after the neonatal arterial switch operation

\begin{tabular}{|c|c|c|c|c|c|c|}
\hline & Total & ASO & ASO/VSD & Complex & F or $t$ & $P$ value \\
\hline Total cohort & $\mathrm{n}=65$ & $\mathrm{n}=36$ & $\mathrm{n}=19$ & $\mathrm{n}=10$ & & \\
\hline FSIQ & $95(17)$ & $94(19)$ & $99(16)$ & $93(12)$ & 0.676 & .513 \\
\hline VIQ & $95(19)$ & $92(19)$ & $101(21)$ & $94(15)$ & 1.126 & .331 \\
\hline PIQ & $95(16)$ & $95(19)$ & $97(13)$ & $90(11)$ & 0.559 & .575 \\
\hline VMI & $94(16)$ & $95(16)$ & $95(17)$ & $87(16)$ & 1.146 & .324 \\
\hline Subgroup without language disorder & $\mathrm{n}=58$ & $\mathrm{n}=31$ & $\mathrm{n}=17$ & $\mathrm{n}=10$ & & \\
\hline FSIQ & $98(16)$ & $97(17)$ & $101(15)$ & $92(12)$ & 0.959 & .389 \\
\hline VIQ & $98(17)$ & $96(17)$ & $104(18)$ & $94(15)$ & 1.579 & .215 \\
\hline PIQ & $96(15)$ & $97(19)$ & $97(13)$ & $90(11)$ & 1.022 & .367 \\
\hline VMI & $94(14)$ & $97(12)$ & $97(14)$ & $87(16)$ & 2.353 & .105 \\
\hline Subgroup with language disorder & $\mathrm{n}=7$ & $\mathrm{n}=5$ & $\mathrm{n}=2$ & $\mathrm{n}=0$ & & \\
\hline FSIQ & $76(23)$ & $75(24)$ & $81(27)$ & - & 0.105 & .760 \\
\hline VIQ & $69(19)$ & $69(19)$ & $69(28)$ & - & 0.001 & .978 \\
\hline PIQ & $85(26)$ & $83(29)$ & $92(23)$ & - & 0.157 & .709 \\
\hline VMI & $85(31)$ & $87(32)$ & $79(42)$ & - & 0.079 & .790 \\
\hline
\end{tabular}

Values are presented as means (standard deviation). ASO, Arterial switch operation; ASO/VSD, arterial switch operation with ventricular septal defect repair; FSIQ, full-scale intelligence quotient; $V I Q$, verbal intelligence quotient; $P I Q$, performance intelligence quotient; $V M I$, visual-motor integration.

Comparing psychologic tests for those 61 without autism and 4 with autism shows the following: FSIQ—97 (16; without autism) versus 67 (19; with autism), $t=3.706, P<.001$; VIQ-97 (18; without autism) versus 64 (17; with autism), $t=3.722, P<.001$; PIQ-96 (15; without autism) versus 75 (26; with autism), $t=2.721, P=.008$; and VMI-95 (16; without autism) versus $76(21$; with autism), $t=$ $2.410, P=.019$.

\section{Prediction of Outcomes for Children With and Without Autism}

Data of 4 children with autism were removed before analysis of predictor variables for psychologic test results. For the 61 children without autism, Table 4 shows the variables from
Table E1 associated with psychologic test results at a $P$ value of .10 or less. After adjusting, few variables remain significantly related to the psychologic scores (Table 5). These remaining variables were sequentially entered into stepwise multiple regression analyses to show changes in the percentage of variance explained by each additional variable and the cumulative variances explained by the combination of these variables (Table 5). Of the variables in Table E1, only mother's education, gestational age, and day 1 highest plasma lactate value combine to explain intelligence scores. This latter variable, the only likely modifiable variable, explains less than $10 \%$ of the variance of these scores. The variables that combine to explain VMI scores are similar to those predicting the intelligence quotients but include septostomy,

TABLE 3. Characteristics of 7 normal-hearing preschool children after the neonatal arterial switch operation who had language disorders diagnosed clinically by speech-language pathologists

\begin{tabular}{|c|c|c|c|c|c|c|c|}
\hline \multirow[b]{2}{*}{ Characteristics } & \multicolumn{7}{|c|}{ Children } \\
\hline & 1 & 2 & 3 & 4 & 5 & 6 & 7 \\
\hline Normal first neurodevelopmental assessment (mo)* & 7 & 8 & 7 & 6 & 7 & 10 & 7 \\
\hline \multicolumn{8}{|l|}{ Language tests used for assessments } \\
\hline PLS 3 or 4/CELF 3 or 4/TOLD-P- & + & + & & + & + & + & + \\
\hline PLAI II/TLC-E & + & & & & & & \\
\hline REEL-2/PPVT-III/BBCA-R/SPELT-P & + & + & + & + & & & \\
\hline CSBS/CCC-2 & + & & + & & & + & + \\
\hline Clinical diagnosis of communication disorder & + & + & + & + & + & + & + \\
\hline Testing done for possible autism spectrum disorder & + & & + & + & + & + & + \\
\hline \multicolumn{8}{|l|}{ Assessment supporting the diagnosis of autism spectrum disorder } \\
\hline DSM-IV & + & & + & - & - & + & + \\
\hline ADOS/ADI-R & + & & + & - & - & + & + \\
\hline GADS/CARS & & & + & & + & & \\
\hline Behavioral history suggestive of social interaction difficulties & + & + & + & + & + & + & + \\
\hline Sibling with history of autism spectrum disorder $\dagger$ & & & & + & & + & + \\
\hline
\end{tabular}

See Table E2 for language test reference list and definition of test abbreviations. *First follow-up visit: patient seen by neurodevelopmental pediatrician, nurse, audiologist, physical therapist. †Each has an older brother with Asperger's syndrome. +, Positive test response; -, negative test response. DSM-IV, Diagnostic and Statistical Manual of Mental Disorders-fourth edition ${ }^{20} ; A D O S$, Autism Diagnostic Observation Schedule ${ }^{18} ; A D I-R$, Autism Diagnostic Interview-Revised. ${ }^{19}$ (see Table E2 for reference list). 
TABLE 4. Significant $(P<.10)$ variables found by means of linear regression analysis to be associated with 5 -year psychologic test results after the neonatal arterial switch operation for the 61 children without autism spectrum disorder

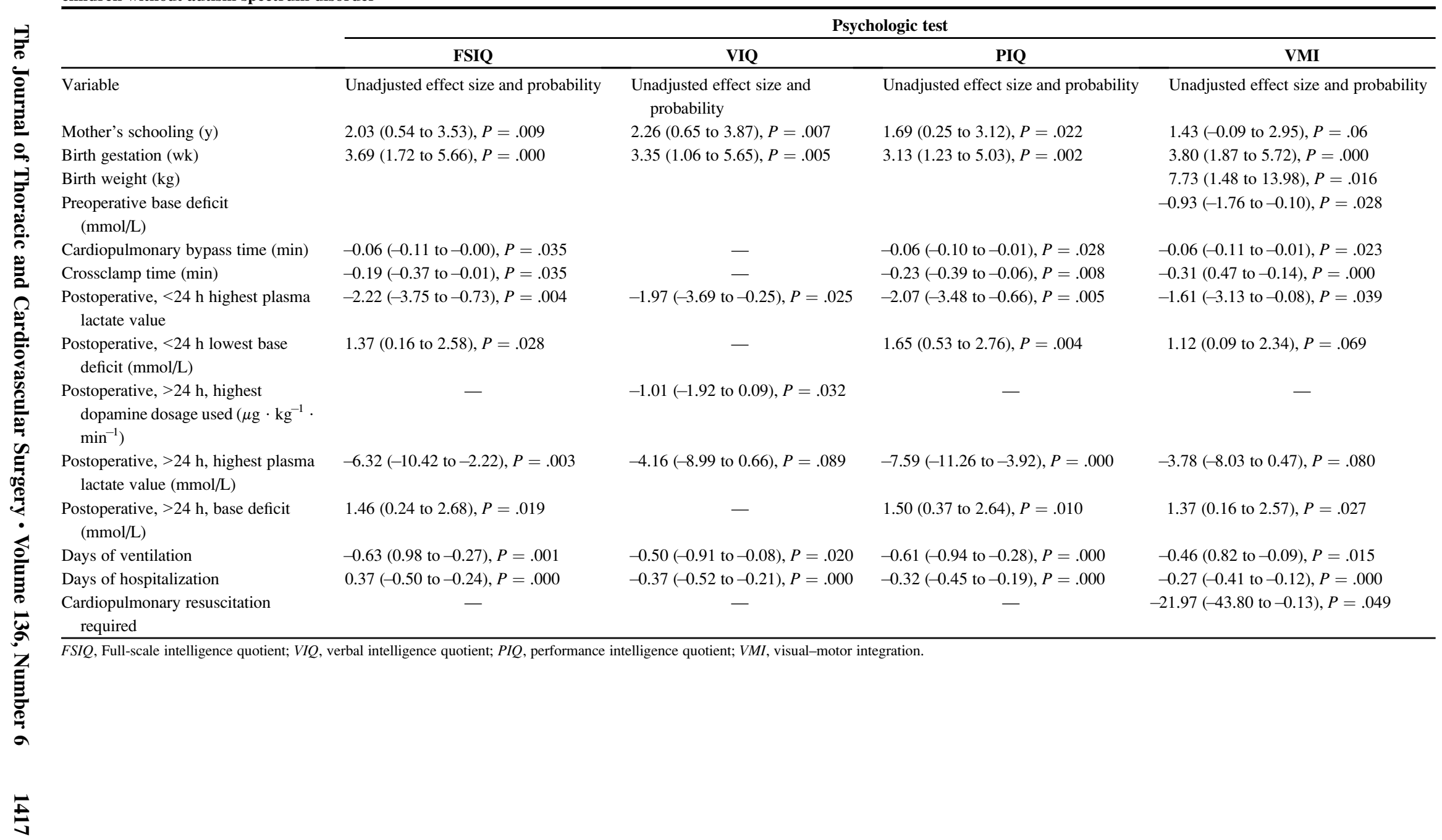


TABLE 5. Sequential stepwise multiple regression analysis of predictor variables* for each psychologic test for the 61 five-year-old children without autism spectrum disorder after the neonatal arterial switch operation

\begin{tabular}{|c|c|c|c|c|c|c|c|c|}
\hline & \multicolumn{2}{|c|}{ FSIQ } & \multicolumn{2}{|c|}{ VIQ } & \multicolumn{2}{|c|}{ PIQ } & \multicolumn{2}{|c|}{ VMI } \\
\hline & $\begin{array}{c}\text { Adjusted effect } \\
\text { size and } \\
\text { probability }\end{array}$ & $\begin{array}{c}\text { Change in \% } \\
\text { variance }\end{array}$ & $\begin{array}{c}\text { Adjusted effect } \\
\text { size and } \\
\text { probability }\end{array}$ & $\begin{array}{c}\text { Change in } \% \\
\text { variance }\end{array}$ & $\begin{array}{c}\text { Adjusted effect } \\
\text { size and } \\
\text { probability }\end{array}$ & $\begin{array}{c}\text { Change in \% } \\
\text { variance }\end{array}$ & $\begin{array}{c}\text { Adjusted } \\
\text { effect size and } \\
\text { probability }\end{array}$ & $\begin{array}{c}\text { Change in \% } \\
\text { variance }\end{array}$ \\
\hline $\begin{array}{l}\text { Mother's } \\
\text { schooling (y) }\end{array}$ & $\begin{array}{c}1.38 \text { (0.04 to } 2.80) \\
P=.057\end{array}$ & $\begin{array}{l}11.1 \% \\
P=.009\end{array}$ & $\begin{array}{c}1.56(0.15 \text { to } 3.26) \\
P=.072\end{array}$ & $9.6 \%, P=.015$ & - & - & $\begin{array}{c}1.44(0.07 \text { to } 2.81) \\
P=.040\end{array}$ & $5.7 \%, P=.06$ \\
\hline $\begin{array}{l}\text { Birth gestation } \\
\quad(w k)\end{array}$ & $\begin{array}{c}2.63 \text { (0.65 to } 4.62) \\
P=.010\end{array}$ & $\begin{array}{l}11.7 \% \\
P=.004\end{array}$ & $\begin{array}{c}2.25(0.12 \text { to } 4.63) \\
P=.063\end{array}$ & $6.9 \%, P=.032$ & $\begin{array}{c}2.78 \text { (0.95 to } 4.61) \\
P=.004\end{array}$ & $\begin{array}{l}15.5 \% \\
P=.002\end{array}$ & - & - \\
\hline $\begin{array}{l}\text { Birth weight } \\
\quad(\mathrm{kg})\end{array}$ & - & - & - & - & - & - & $\begin{array}{l}6.46(0.70 \text { to } 12.21) \\
\quad P=.029\end{array}$ & $8.4 \%, P=.02$ \\
\hline Septostomy & - & - & - & - & - & - & $\begin{array}{l}9.01 \text { (1.95 to } 16.07) \\
\quad P=.013\end{array}$ & $7 \%, P=.03$ \\
\hline $\begin{array}{l}\text { Postoperative, } \\
\quad<24 \mathrm{~h} \text { highest } \\
\text { plasma lactate } \\
\text { value } \\
(\mathrm{mmol} / \mathrm{L})\end{array}$ & $\begin{array}{r}-1.96(-3.31 \\
\text { to }-0.60) \\
P=.005\end{array}$ & $9.9 \%, P=.005$ & $\begin{array}{c}-1.74(-3.37 \text { to } \\
-0.12) \\
P=.036\end{array}$ & $6.3 \%, P=.036$ & $\begin{array}{c}-1.78(-3.11 \text { to } \\
-0.44) \\
P=.010\end{array}$ & $9.2 \%, P=.01$ & $\begin{array}{c}-1.65(-3.04 \text { to } \\
-0.26) \\
P=.021\end{array}$ & $7.2 \%, P=.02$ \\
\hline $\begin{array}{l}\text { Percentage } \\
\quad \text { of variance } \\
\text { explained by } \\
\text { the multiple } \\
\text { regression } \\
\text { model }\end{array}$ & & $32.7 \%$ & & $22.8 \%$ & & $24.1 \%$ & & $28.3 \%$ \\
\hline
\end{tabular}

psychologic test results from Table 4. 
which explains an additional $7 \%$ of the variance, as well as birth weight instead of gestational age.

The variable DHCA was not included in Table 4 because the duration of DHCA did not reach a significant level of unadjusted effect size on univariate analysis. However, all 5 of the children with PIQ scores of less than 70 had DHCA. Of the 33 children requiring DHCA, 5 (15\%) had PIQ scores of less than 70 compared with no PIQ scores of less than 70 for those 32 children without DHCA (exact sig $=.053$ ).

\section{Children With Autism}

All variables from Table E1 were compared for the children with and without autism. Differences were found only in preoperative highest plasma lactate values $(7[6] \mathrm{mmol} / \mathrm{L}$ [with autism] vs 4 [7] $\mathrm{mmol} / \mathrm{L}$ [without autism], $t=$ $-2.215, P=.03)$ and DHCA time $(\mathrm{n}=33 ; 7$ [3] minutes [with autism] vs 19 [20] minutes [without autism], $t=$ $2.945, P=.006$ ). All 4 children with autism had intact ventricular septum and the ASO, resulting in a prevalence of $11 \%$ in this subgroup. Three of the 4 children with autism had septostomy, and 2 of these required DHCA. The fourth child had DHCA without septostomy. None of the 4 with autism had an antenatal diagnosis of TGA; required repeat CPB in the operating room, extracorporeal membrane oxygenation, cardiopulmonary resuscitation, or reintervention; or had convulsions. Two children with autism and 1 child with an LD without autism have a sibling with Asperger's syndrome. A retrospective review of charts revealed no other child had a sibling with autism. Genetic investigations were negative for karyotype, Fragile X, del 22q.11.2 in 4 children with autism and also for Rett syndrome in 1 girl. Three children with autism had a normal magnetic resonance image on hospital discharge, and 1 had a small subependymal hemorrhage; this latter child and one of the other children with autism had repeated normal magnetic resonance image results.

We assessed whether any variables were predictive for autism. The only variables significantly related to autism at a $P$ value of less than .10 in univariate logistic regression analysis were having a sibling with autism and highest preoperative plasma lactate value. In the multiple logistic regression model the odds for autism were 7.18 times higher for patients having a sibling diagnosed with autism (odds ratio, 7.18; confidence interval, 3.71-1389.41; $P=.005)$. After adjusting for children having a sibling with autism, the odds ratio of autism corresponding to the highest preoperative plasma lactate value was 1.27 (confidence interval, $0.99-1.61)$, with marginal significance $(P=.057)$.

\section{DISCUSSION}

This article confirms the low mortality previously reported $^{13,22}$ and adds to previous publications ${ }^{3,6}$ on the preschool outcomes after the ASO by presenting data from a later surgical era. In keeping with past publications, ${ }^{3,13}$ children with diagnoses such as postdischarge meningitis and au- tism considered to be unrelated to the perioperative period were excluded from predictive analysis. The finding that 4 $(6 \%)$ of the 65 children in the cohort had autism is unusual.

This article suggests that after the ASO for TGA, children at 5 of years of age are similar to their peers in terms of growth and health parameters, with few exceptions. Two (3\%) of 65 children had motor impairment linked to preoperative complications, and $17(26 \%)$ children had speech difficulties, language difficulties, or both. Seven $(11 \%)$ of 65 children had LD. Cognitive ability for the total cohort, and more specifically for those without $\mathrm{LD}$, compares favorably with the published literature. ${ }^{3,6,9,10}$ Those with LD differed significantly from those without LD on their FSIQ and VIQ measurements, which is in keeping with their diagnosis. They demonstrated relative strength but with wide variability in nonverbal areas. Four of the 7 children with LD were given diagnoses of autism characterized by deficits in social interaction, impaired communication, and restricted or repetitive interests and behaviours. ${ }^{20}$ These children differed significantly from the remainder of the cohort on all psychologic measures, including the nonverbal measures.

Stepwise multiple regression analyses of the 5-year psychologic scores for children without autism show that less than one third of the variance within the scores can be explained by the studied variables. Mother's education is a predictor. Low birth weight is also related to outcomes, which is consistent with other reports. ${ }^{22}$ The highest plasma lactate value within the first postoperative day explains $6 \%$ to $10 \%$ of the variance in intelligence scores and supports previous findings. ${ }^{23}$ Because this is a potentially modifiable variable, further investigation into causes of high lactate values could lead to improved outcomes. Similar to the prediction of intelligence scores, only $26 \%$ of the variation in VMI scores was explained by the studied variables; the use of septostomy contributed $7 \%$ and was associated with lower scores. There is potential for improvement with further study of brain insult associated with septostomy ${ }^{24}$ or the underlying hypoxia contributing to its use.

This study found a high percentage of children with speech and language difficulties. Children who have undergone the ASO for TGA have been reported to have significantly greater language difficulties compared with the general population, despite cognitive abilities in the average range. ${ }^{3,4,6,8,9}$ Although structural aspects of language (vocabulary and syntax) appear intact, specific difficulties with symbolic talk during play and storytelling, particularly with describing the story character's internal affective states, are at risk..$^{11,12}$

We found an unexpectedly high rate of autism in our sample of children undergoing the ASO, roughly 10 times higher than current prevalence estimates of 6 per $1000 .{ }^{25}$ Diagnosable medical conditions, syndromes, and single-gene disorders make up less than $10 \%$ of autism diagnoses. ${ }^{25,26}$ Evidence from family and twin studies suggests that "idiopathic" 
autism is highly inheritable because of interactions of multiple genes modified by epigenetic and environmental factors. ${ }^{26} \mathrm{In}$ this study 2 of the 4 children with autism had an older sibling with Asperger's syndrome. Hence the increased rate of autism in our cohort might partly be related to overrepresentation of related disorders among siblings. In addition, 1 of the 3 children with LD had a sibling with autism.

Several studies have investigated prenatal and perinatal risk factors associated with autism. ${ }^{27,28}$ High preoperative plasma lactate values, a surrogate measure of tissue hypoperfusion, was the only medical variable that was more abnormal among children with autism in this study. This variable had marginal predictive significance in multivariate analysis. However, all 4 children with autism had TGA with an intact ventricular septum, a group at risk for increased hypoxia. The septostomy received by 3 of the 4 children with autism is also linked to preoperative brain injury. ${ }^{24}$ Specific brain injury is not supported for these children because brain imaging was within normal limits. In children with TGA, abnormal fetal circulation and brain oxygenation, neonatal hypoxia, and surgical risks are well known. ${ }^{29}$ Abnormal brain microstructure and metabolism have been reported in newborns with congential heart disease. ${ }^{30}$ Any of these insults can interact with a genetic predispostion to lead to autism. TGA is generally considered an isolated cardiac malformation that is rarely associated with genetic syndromes. However, should the association of TGA and autism in this article be confirmed, this might indicate a shared genetic susceptibility or shared environmental insult during development.

The strengths of this study are the high proportion of children, $95.5 \%$ of survivors, available at 5 years for individual assessment and the prospectively collected predictive variables. Although follow-up occurred at 5 centers, all assessors were certified, protocols were closely followed, and the centers have worked as a multisite research team since 1996. A limitation of this article is the small number of subjects with complex forms of TGA; however, some studies do not include these children, ${ }^{3,4}$ and this study provides an opportunity to view their outcomes. The major limitation of the study is that not all children were seen by a speech-language pathologist, and thus the speech and language diagnoses might underestimate the proportion of children with these difficulties. Also, not all parents were asked about a family history of autism, although all were asked whether there were child development or mental health concerns in the extended family. No comparison subjects are available for this study, but standardized measures with population-normative data are used throughout.

\section{CONCLUSIONS}

After the ASO, preschool children have cognitive skills within population norms. However, we report an increased incidence of LD, supporting concern about discourse abilities. Follow-up of children after the neonatal ASO should include a complete speech and language evaluation, with particular attention to social use of language and family history of LD, autism, or both. Investigation into a possible genetic link between TGA and autism is recommended. The importance of mother's schooling as a predictor of psychologic test results, the link of TGA with autism, and the minimal effect of intraoperative variables on cognitive scores support a strong genetic influence in the outcome of these children.

We thank the families of these children for their active participation in the developmental sites across western Canada and their commitment to this project. We sincerely thank the research and data coordinators and psychologists who made this research study possible: H. Christianson and D. Anseeuw-Deeks, Calgary, Alberta, Canada; K. Penner, J. Bow, and V. Debooy, Winnipeg, Manitoba, Canada; B. Acton, Saskatoon, Saskatchewan, Canada; S. Selzer and H. Switzer, Regina, Saskatchewan, Canada; and Jill Tomlinson, G. Alton, and W. Biggs, Edmonton, Alberta, Canada.

\section{References}

1. Wernovsky G. Current Insights regarding neurological and developmental abnormalities in children and young adults with complex congenital heart disease. Cardiol Young. 2006;16(suppl 1):92-104.

2. Ballweg JA, Wernovsky G, Gaynor JW. Neurodevelopmental outcomes following congenital heart surgery. Pediatr Cardiol. 2007;28:126-33.

3. Bellinger D, Wypij D, Kuban K, Rappaport LA, Hickey PR, Wernovsky G, et al. Development and neurological status of children at 4 years after heart surgery with hypothermic circulatory arrest or low-flow cardiopulmonary bypass. Circulation. 1999; 100:526-32.

4. Bellinger D, Wypij D, duPlessis AJ, Rappaport LA, Jonas RA, Wernovsky G, et al. Neurodevelopmental status at eight years in children with dextro-transposition of the great arteries: the Boston Circulatory Arrest Trial. J Thorac Cardiovasc Surg. 2003;126:1385-96.

5. Wypij D, Newburger J, Rappaport L, du Plessis AJ, Jonas RA, Wernovsky G, et al. The effect of duration of deep hypothermic circulatory arrest in infant heart surgery on late neurodevelopment: the Boston Circulatory Arrest Trial. J Thorac Cardiovasc Surg. 2003;126:1397-403.

6. Hövels-Gürich H, Seghaye M, Däbritz S, Messmer B, von Bernuth G. Cognitive and motor development in preschool and school-aged children after neonatal arterial switch operation. J Thorac Cardiovasc Surg. 1997;114:578-85.

7. Hövels-Gürich H, Seghaye M-C, Schnitker R, Wiesner M, Hube W, Minkenberg R, et al. Long-term neurodevelopmental outcomes in school-aged children after neonatal arterial switch operation. $J$ Thorac Cardiovasc Surg. 2002; $124: 448-58$

8. Hövels-Gürich H, Konrad K, Wiesner M, Minkenberg R, Herpetz-Dahlmann B, Messmer B, et al. Long term behavioural outcome after neonatal arterial switch operation for transposition of the great arteries. Arch Dis Child. 2002;87:506-10.

9. Karl T, Hall S, Ford G, Kelly EA, Brizard CPR, Mee RBB, et al. Arterial switch with full-flow cardiopulmonary bypass and limited circulatory arrest: neurodevelopmental outcome. J Thorac Cardiovasc Surg. 2004;127:213-22.

10. Creighton DE, Robertson CMT, Sauve RS, Moddemann DM, Alton GY, NettelAguire A, et al. Neurocognitive, functional, and health outcomes at 5 years of age for children after complex cardiac surgery at 6 weeks of age or younger. Pediatrics. 2007;120:e478-86.

11. Ovadia R, Hemphill L, Winner K, Bellinger D. Just pretend: participation in symbolic talk by children with histories of early corrective heart surgery. Appl Psycholinguist. 2000;21:321-40.

12. Hemphill L, Uccelli P, Winner K, Chang D, Bellinger D. Narrative discourse in children with early corrective heart surgery. J Speech Lang Hear Res. 2002;45: 318-31.

13. Freed DH, Robertson CMT, Sauve RS, Joffe AR, Rebeyka IM, Ross DB, et al. Intermediate-term outcomes of the arterial switch operation for transposition of great arteries in neonates: alive but well? J Thorac Cardiovasc Surg. 2006;132: $845-52$. 
14. Blishen BR, Carroll WK, Moore C. The 1981 socioeconomic index for occupations in Canada. Can Rev Soc Anth. 1987;24:465-88.

15. Weschler D. Weschler Preschool and Primary Scales of Intelligence-3rd edition. San Antonio, Tex: Psychological Corporation; 2002.

16. Beery KE. The Beery-Buktenica Developmental Test of Visual-Motor Integration. 4th ed. Revised. Parsinppany, NJ: Modern Curriculum Press; 1997.

17. Reed VA. An overview of children's language disorders. In: Reed VA, ed. An introduction to children with language disorders. New York: MacMillan Publishing Co; 1986:65-79.

18. Lord C, Risi S, Lembrecht LCE, Cook EH Jr, Leventhal BL, Dilawore PC, et al. The Autism Diagnostic Observation Schedule-Generic: a standard measure of social and communication deficits associated with the spectrum of autism. J Autism Dev Disord. 2000;30:205-23.

19. LeCouteur A, Lord C, Rutter M. Autism Diagnostic Interview-Revised (ADI-R). Los Angeles: Western Psychological Services; 2003.

20. American Psychiatric Association. Diagnostic and statistical manual of mental disorders. 4th ed. Washington, DC: American Psychiatric Association; 1994.

21. Cohen J, Cohen P. Applied multiple regression/correlation analysis for the behavioural sciences. 2nd ed. Hillsdale, NJ: Erlbaum; 1983. p. 79-132.

22. Qamar ZA, Goldberg CS, Devany EJ, Bove EL, Ohye R. Current risk factors and outcomes for the arterial switch operation. Ann Thorac Surg. 2007;84: 871-9.
23. Cheung PY, Chui N, Joffe AR, Rebeyka IM, Robertson CM. Postoperative lactate concentrations predict the outcome of infants aged 6 weeks of less after intracardiac surgery: a cohort follow-up to 18 months. J Thorac Cardiovasc Surg. 2005; 130:837-43.

24. McQuillen PS, Hamrick SEG, Perez MI, Barkovich J, Glidden DV, Karl TR, et al. Balloon atrial septostomy is associated with preoperative stroke in neonates with transposition of the great arteries. Circulation. 2006;113:280-5.

25. Fombonne E. Epidemiology of autistic disorder and other pervasive developmental disorders. J Clin Psychiatry. 2005;66(suppl 10):3-8.

26. Muhle R, Trentacoste SV, Rapin I. The genetics of autism. Pediatrics. 2004;113 472-86.

27. Larsson HJ, Eaton WW, Madsen KM, Westergaard M, Olesen AV, Agerbo E, et al. Risk factors for autism: perinatal factors, parental psychiatric history, and socioeconomic status. Am J Epidemiol. 2005;161:916-25.

28. Zwaigenbaum L, Szartmari P, Jones MB, Bryson SE, MacLean JE, Mahoney WJ, et al. Pregnancy and birth complications and liability to the broader autistic phenotype. J Am Acad Child Adolesc Psychiatry. 2002;41:572-9.

29. du Plessis AJ. Mechanisms of brain injury during infant cardiac surgery. Semin Pediatr Neurol. 1999;6:32-47.

30. Miller SP, McQuillen PS, Hamrick S, Xu D, Glidden DV, Charlton N, et al. Abnormal brain development in newborns with congenital heart disease. $N$ Engl J Med. 2007;357:1928-38. 
TABLE E1. Characteristics of 65 survivors undergoing the neonatal arterial switch operation in relation to complexity of cardiac anomaly

\begin{tabular}{|c|c|c|c|c|c|c|}
\hline & $\begin{array}{c}\text { Total } \\
(n=65)\end{array}$ & $\begin{array}{c}\text { ASO } \\
(n=36)\end{array}$ & $\begin{array}{c}\text { ASO/VSD } \\
(n=19)\end{array}$ & $\begin{array}{c}\text { Complex } \\
(n=10)\end{array}$ & F or $\chi^{2}$ & $P$ value* \\
\hline \multicolumn{7}{|l|}{ Preoperative } \\
\hline Socioeconomic status $\dagger$ & $42(12)$ & $42(14)$ & $44(10)$ & $42(12)$ & 0.264 & .769 \\
\hline Mother's schooling (y) & $13(3)$ & $13(3)$ & $13(5)$ & $12(2)$ & 0.224 & .800 \\
\hline Male sex & $42(65 \%)$ & $23(55 \%)$ & $13(31 \%)$ & $6(14 \%)$ & 0.222 & .895 \\
\hline Year of operation & $1999.9(2.0)$ & $1999.5(2.1)$ & $2000.8(1.7)$ & $1999.5(1.8)$ & 3.106 & .052 \\
\hline Antenatal diagnosis & $6(9 \%)$ & $2(6 \%)$ & $4(21 \%)$ & $0(0 \%)$ & 4.766 & .092 \\
\hline Age at operation (d) & $11(7)$ & $10(7)$ & $10(8)$ & $14(7)$ & 1.336 & .270 \\
\hline Birth gestation (wk) & $39(2)$ & $39(2)$ & $39(1)$ & $38(3)$ & 0.972 & .384 \\
\hline Birth weight $(\mathrm{kg})$ & $3.4(0.6)$ & $3.3(0.5)$ & $3.4(0.5)$ & $3.5(1.0)$ & 0.128 & .880 \\
\hline Balloon septostomy & $35(54 \%)$ & $24(68 \%)$ & $8(42 \%)$ & $3(30 \%)$ & 5.723 & .057 \\
\hline Ventilation $(\mathrm{d})$ & $5(4)$ & $4(4)$ & $4(3)$ & $6(8)$ & 1.103 & .338 \\
\hline Highest dopamine used $\left(\mu \mathrm{g} \cdot \mathrm{kg}^{-1} \cdot \min ^{-1}\right)$ & $4.4(7.2)$ & $5.9(8.2)$ & $3.4(5.9)$ & $1.1(3.2)$ & 2.183 & .121 \\
\hline Highest plasma lactate value (mmol/L) & $3.6(3.3)$ & $4.0(3.8)$ & $3.5(2.7)$ & $2.0(1.4)$ & 1.610 & .208 \\
\hline Lowest base deficit (mmol/L) & $-4.4(4.7)$ & $-5.6(4.3)$ & $-4.1(3.9)$ & $-0.3(5.6)$ & 5.744 & .005 \\
\hline \multicolumn{7}{|l|}{ Operative } \\
\hline Cardiopulmonary bypass time (min) & $137(74)$ & $123(75)$ & $136(21)$ & $190(113)$ & 3.463 & .038 \\
\hline Lowest flow for $>10 \min \left(\mathrm{mL} \cdot \mathrm{kg}^{-1} \cdot \mathrm{min}^{-1}\right)$ & $104(30)$ & $105(34)$ & $107(29)$ & $95(14)$ & 0.604 & .550 \\
\hline Crossclamp time (min) & $68(22)$ & $57(16) \ddagger \S$ & $74(12)$ & $96(26)$ & 21.979 & $<.001$ \\
\hline Lowest temperature during $\mathrm{CPB}\left({ }^{\circ} \mathrm{C}\right)$ & $\begin{array}{c}25(3) ; \\
\text { range, } 19-29\end{array}$ & $25(3) \ddagger$ & $26(2) \ddagger$ & $23(3)$ & 4.855 & .011 \\
\hline DHCA used & $33(50 \%)$ & $27(75 \%)$ & $2(11 \%)$ & $4(40 \%)$ & 21.232 & $<.001$ \\
\hline DHCA time $(\min ; \mathrm{n}=33)$ & $18(19)$ & $16(18)$ & $15(10)$ & $37(24)$ & 2.315 & .116 \\
\hline Lowest temperature just before DHCA $\left({ }^{\circ} \mathrm{C}\right)$ & $\begin{array}{c}23(2) ; \\
\text { range, } 19-27\end{array}$ & $23(2)$ & $21(0.4)$ & $22(3)$ & 1.059 & .359 \\
\hline Need for re-CPB & $7(11 \%)$ & $1(3 \%)$ & $1(5 \%)$ & $5(50 \%)$ & 19.008 & $<.001$ \\
\hline \multicolumn{7}{|l|}{ Postoperative, $<24 \mathrm{~h}$} \\
\hline Highest dopamine used $\left(\mu \mathrm{g} \cdot \mathrm{kg}^{-1} \cdot \min ^{-1}\right)$ & $7.6(4.7)$ & $7.5(3.8)$ & $8.0(5.8)$ & $7.1(5.8)$ & 0.106 & .900 \\
\hline Highest plasma lactate $(\mathrm{mmol} / \mathrm{L})$ & $5.3(2.6)$ & $5.5(2.3)$ & $5.1(3.0)$ & $5.0(2.6)$ & 0.246 & .783 \\
\hline Lowest base deficit (mmol/L) & $0.88(3.2)$ & $1.7(3.2) \S$ & $-1.0(2.4)$ & $1.5(3.6)$ & 5.093 & .009 \\
\hline \multicolumn{7}{|l|}{ Postoperative $>24 \mathrm{~h}$} \\
\hline $\begin{array}{l}\text { Highest dopamine dosage used } \\
\qquad\left(\mu \mathrm{g} \cdot \mathrm{kg}^{-1} \cdot \min ^{-1}\right)\end{array}$ & $7.1(4.9)$ & $7.4(4.6)$ & $6.4(5.6)$ & $7.6(4.7)$ & 0.293 & .747 \\
\hline Highest plasma lactate value $(\mathrm{mmol} / \mathrm{L})$ & $2.1(0.9)$ & $1.9(0.8)$ & $2.5(1.2)$ & $2.1(0.7)$ & 2.143 & .126 \\
\hline Lowest base deficit (mmol/L) & $1.4(3.3)$ & $2.1(3.4)$ & $0.1(2.4)$ & $1.6(3.9)$ & 2.187 & .121 \\
\hline \multicolumn{7}{|l|}{ Overall } \\
\hline Duration of ventilation (d) & $9(10)$ & $8(12)$ & $9(9)$ & $11(7)$ & 0.378 & .686 \\
\hline Duration of hospitalization (d) & $27(25)$ & $27(26)$ & $26(26)$ & $29(17)$ & 0.065 & .937 \\
\hline Clinical convulsions occurred & $4(6 \%)$ & $3(8 \%)$ & $1(5 \%)$ & $0(0 \%)$ & 0.978 & .613 \\
\hline Cardiopulmonary resuscitation required & $2(3 \%)$ & $0(0 \%)$ & $0(0 \%)$ & $2(20 \%)$ & 11.349 & .003 \\
\hline Extracorporeal membrane oxygenation used & $2(3 \%)$ & $1(3 \%)$ & $0(0 \%)$ & $1(10 \%)$ & 2.221 & .329 \\
\hline Reintervention & $6(9 \%)$ & $1(3 \%)$ & $2(11 \%)$ & $3(30 \%)$ & 6.976 & .031 \\
\hline
\end{tabular}

Values are presented as means (standard deviations) or number (percentage). Note: After the Bonferonni correction, $P$ values of .001 or less remain significant. $A S O$, Isolated arterial switch operation; $A S O / V S D$, ASO with ventricular septal defect repair; $C P B$, cardiopulmonary bypass; $D H C A$, deep hypothermic circulatory arrest. *One-way analysis of variance or $\chi^{2}$ analysis. $\dagger$ Mean (SD) $=43(13)$; Blishen and colleagues. ${ }^{14} \pitchfork$ Significant difference from the complex group $(P<.01)$. $\S$ Significant difference from the ASO/VSD group $(P<.01)$. 
TABLE E2. References for language measures

CARS Schopler E, Reichler RJ, Renner BR. The Childhood Autism Rating Scale. Los Angeles, Calif: Western Psychological Services; 1988.

CELF3 or 4 Semel EM, Wiig EH, Secord W. Clinical Evaluation of Language Fundamentals-third edition. San Antonio, Tex: The Psychological

Corporation; 1995.

Semel EM, Wiig EH, Secord W. Clinical Evaluation of Language Fundamentals-fourth edition. San Antonio, Tex: The Psychological Corporation; 2003.

CSBS Wetherby AM, Prizant BM. Communication and Symbolic Behaviour Scales Developmental Profile: first normed edition. Baltimore, Md: Brookes Publishing Co; 2002.

GADS Gilliam JE. Gilliam Asperger's Disorder Scale. Austin, Tex: PRO-ED; 2001.

PPVT-III Dunn LM, Dunn LM. Peabody Picture Vocabulary Test, third edition. Bloomington, Minn: Pearson; 1997.

PLAI-II Blank M, Rose SA, Berlin LJ. Preschool Language Assessment Instrument, second edition. Austin, Tex: Pro-Ed; 2003.

PLS 3 or 4 Zimmerman IL, Steiner VG, Pond RE. Preschool Language Scale, third edition. San Antonio, Tex: The Psychological Corporation; 1992.

Zimmerman IL, Steiner VG, Pond RE. Preschool Language Scale, fourth edition. San Antonio, Tex: The Psychological Corporation; 2002.

REEL-2 Bzoch KR, League R. Receptive Expressive Emergent Language Test, second edition. Austin, Tex: Pro-Ed; 1991.

SPELT-P Dawson J, Stout C, Eyer J, Tattersall P, Fonkalsrud J, Croley K. Structured Photographic Expressive Language Test Preschool-2nd edition. San Antonio, Tex: Harcourt Assessment; 2004.

TAPS-R Gardner MF. Test of Auditory Perceptual Skills-Revised. Hydesville, Calif: Psychological and Educational Publications; 1996.

TLC-E Wiig EH, Secord W. Test of Language Competence-Expanded Edition. San Antonio, Tex: The Psychological Corporation; 1989.

TOLD-P-3 Newcomer PL and Hammill DD. Test of Language Development-Primary, third edition. Austin, Tex: PRO-ED; 1997.

BBCS-R Bracken BA. Bracken Basic Concept Scale-Revised. San Antonio, Tex: The Psychological Corporation; 1998.

CCC-2 Bishop DVM. The Children's Communication Checklist-2. San Antonio, Tex: Harcourt Assessment; 2003. 